\title{
CORRIGENDUM
}

\section{Polygamy and an absence of fine-scale structure in Dendroctonus ponderosae (Hopk.) (Coleoptera: Curcilionidae) confirmed using molecular markers}

JK Janes, AD Roe, AV Rice, JC Gorrell, DW Coltman, DW Langor and FAH Sperling

Heredity (2016) 116, 124; doi:10.1038/hdy.2015.87

Correction to: Heredity (2016) 116, 68-74; doi:10.1038/hdy.2015.71; published online 19 August 2015

Since the online publication of this article the authors have noticed that in the final paragraph of the Discussion the citation for Fraser et al. (2014) mistakenly referred to the Dicronorrhina micans beetle species, when it should have been the Dendroctonus micans species.
The authors apologise for any inconvenience caused by this error. This error has now been rectified, and the corrected article appears in this issue. The html and online pdf versions have also been rectified, and now carry the corrected paper. 